\title{
Evaluation of Irradiated Mandibles Using Emission Tomography, Bone Scans, and Radiography
}

\author{
MICHAEL D. ROHRER, ${ }^{*}$ LOUIS T. KIRCOS, JAMES H. THRALL, YOUNG KIM, ** and \\ JUAN V. FAYOS**
}

The University of Michigan Medical Center, Ann Arbor, Michigan 48109

\begin{abstract}
This study compared radiographs, bone scans, and computed emission tomograms with histologic findings in irradiated mandibles of adult Rhesus monkeys. Although osteocytes were lost in the path of the beam, many vessels were partially or totally occluded, the periosteum degenerated, the marrow became fibrotic, and cancellous bone proliferated abundantly, no changes were noted with radiography, conventional bone scanning, or computed emission tomograms. These clinical methods of examination may misrepresent the true condition of irradiated bone because of inadequate sensitivity or balance among factors that control radioactive tracer uptake in bone.
\end{abstract}

J Dent Res 59(12):2032-2037, December 1980

\section{Introduction.}

One of the most severe and complicating sequelae of irradiation for patients with cancer of the head and neck is the development of osteoradionecrosis of the mandible. This investigation studies the effects of radiation on the jaw by observing the morphologic changes induced by a tumoricidal dose of cobalt -60 radiation and correlating these changes with clinical manifestations that can be observed either radiographically, using conventional radioisotopic bone scans, or with computerassisted emission tomography.

The intent of this investigation is to simulate the situation of the human radiation patient. Unlike all other studies of

Received for publication November 26, 1979 Accepted for publication March 31, 1980

*Present address: Department of Oral Pathology, College of Dentistry, The University of Oklahoma Health Sciences Center, P.O. Box 26901, Oklahoma City, OK 73190

**Present address: Radiation Therapy Department, Jackson Memorial Hospital, Miami, FL 33136

This study was supported in part by funds from the National Institutes of Health under NIDR Grant No. 5 TO1-DE00013. irradiated jaws, this is not a study of osteoradionecrosis or socket healing after irradiation. It is an attempt to determine the degree to which experimentally-induced radiation damage of the mandible is detectable by the clinical diagnostic methods of radiography, bone scanning, and computed emission tomography.

\section{Materials and methods.}

This study used ten Rhesus monkeys (Macaca mulatta) ranging in weight from 5.8 to $13.8 \mathrm{~kg}$, and in age from seven to ten years, comparable to 28 to 40 years in human age. Lateral head radiographs were taken of all monkeys prior to any experimentation using a medical $x$-ray unit with a source-film distance of 53 inches and a very high resolution industrial film. ${ }^{*}$ Prior to irradiation, three monkeys were imaged using conventional bone scanning, and one was imaged using computed emission tomography. The monkeys were anesthetized with ketamine hydrochloride and were given $15 \mathrm{mCi}$ of $\mathrm{Tc}-99 \mathrm{~m}$ stannous pyrophosphate three hours prior to imaging.

For imaging, the monkeys were anesthetized with phencyclidine hydrochloride and sodium pentobarbital, since it was essential they did not move. Lateral head scans were performed by a gamma camera and photographs were taken at 300,000 counts. A gamma camera mounted on a teletherapy unit which enabled rotations necessary for the axial symmetry was used for computed emission tomography. ${ }^{1}$ The reconstructions were performed by a scintigraphic computer system ${ }^{\dagger}$ within the Nuclear Medicine Department. ${ }^{2}$

\footnotetext{
* Kodak Industrial Type M Film

$\uparrow$ Medical Data Systems, Ann Arbor, MI
} 
Six monkeys received a mid-plane dose of 450 rads at each treatment, half from the right side, half from the left side, from a cobalt -60 teletherapy unit with an $80 \mathrm{~cm}$ SSD through two pairs of lateral mandibular fields measuring $7 \times 8 \mathrm{~cm}$. Each field was treated daily with a total dose of 4500 rads delivered to the mid-saggital plane in ten fractions over $12 \mathrm{~d}$. This is equivalent to 7000 rads given in 35 fractions over seven wk according to the Time, Dose, Fractionation (T.D.F.) factors calculation of Orton and Ellis. ${ }^{3}$

Two monkeys died one wk post-irradiation. The necropsy report attributed death to dehydration and acute radiation damage. The remaining irradiated monkeys were imaged using conventional imaging procedures at monthly intervals until sacrifice at six mo post-irradiation. One irradiated monkey and two control monkeys were also imaged monthly using computed emission tomography. Lateral head radiographs were taken of all animals before sacrifice. One irradiated monkey was sacrificed at three mo post-irradiation. The remaining monkeys were killed six mo post-irradiation. The mandibles were sectioned at the level of the ramus, third molar, second molar, first molar, premolar, and incisors. They were then fixed, decalcified, embedded in paraffin, and sectioned at $5 \mu \mathrm{m}$.

\section{Results.}

Symptoms and physical changes developed in the monkeys parallel to those seen in human head and neck radiation patients, including severe mucositis, alopecia, inability to eat or drink, weight loss, facial and neck edema, and excess salivation followed by xerostomia.

Histologic observations revealed striking changes in the mandibles. ${ }^{4}$ Compared to the control group and to non-irradiated areas in the experimental group, loss of osteocytes from bone lacunae was seen to a significant degree $(p<.001)$ in the areas in the direct beam path in the outer lamellar and Haversian bone of the mandibular cortex. However, in the cancellous bone, no loss of osteocytes was seen (Fig. 1). In this cancellous region there was marked proliferation of new bone easily detected with a trichrome stain, which stains mature bone red and osteoid and immature bone green. New bone was also seen arising from the endosteum on the inner aspect of the cortical bone, in a few areas from the periosteum on the outer surface of the cortical bone, from cancellous bone trabeculae, and as metaplastic bone arising from the fibrous marrow. A nonhematopoietic fibrous marrow replaced the hematopoietic fatty marrow seen in the control animals.

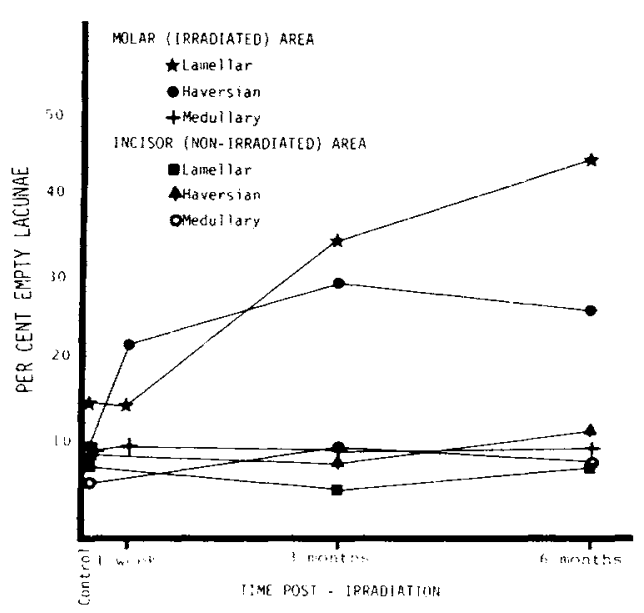

Fig. 1 - Mean percent of empty lacunae plotted against time post-irradiation. No significant loss of osteocytes from cancellous bone within or outside radiation field. Loss of osteocytes is significant $(p<.001)$ in the outer lamellar and Haversian bone within the path of the beam.

Blood vessels of all sizes were dramatically affected with the most striking changes in the arterioles and in the small- and medium-sized arteries. Fibrous plaque formations, central to the internal elastic lamina, encroached upon or obliterated the vessel lumens. In some sections, fibrous plaques completely obliterated the inferior alveolar arteries which are the primary blood supply to the mandible (Fig. 2).

The periosteum within the beam path lost cellularity and vascularity. The normal vesse 1 arrangement in the Haversian canals (one vein and one or two small arterioles) was disrupted. Many vessels were obliterated and many Haversian canals were completely filled with fibrous tissue or osteoid.

The lateral head radiography using a long source-film distance, high resolution industrial film, and an exposure time of 1.5 to 


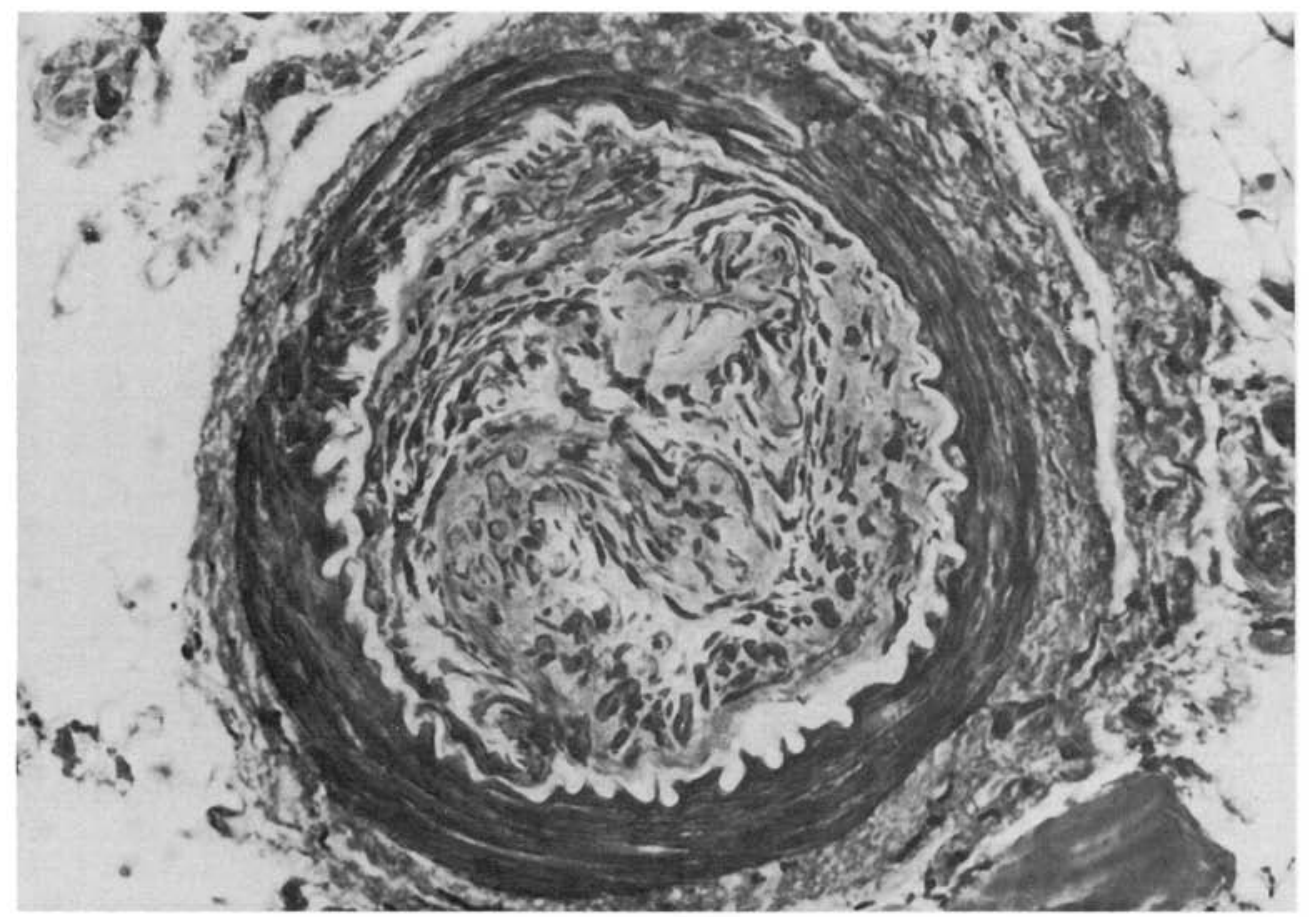

Fig. 2 - Complete occlusion of artery from inferior alveolar group with fibrous plaque. Six mo postirradiation. (Trichrome $\times 200$ )

two $s$ resulted in radiographs with very high resolution. The resolution was much greater than could be obtained with any available methods for clinical intra- or extraoral radiographs, and the fine trabecular pattern could be seen very clearly in the mandible and maxilla. No differences were detected between pre- and post-irradiation films or between irradiated and control animals.

Very satisfactory bone scans resulted from injecting $15 \mathrm{mCi}$ of $\mathrm{Tc}-99 \mathrm{~m}$ stannous pyrophosphate three $\mathrm{h}$ before imaging. Scintophotos were taken at 300,000 counts. The anterior portion of the mandible was spared from irradiation in order to provide an internal control to see if the irradiated and non-irradiated areas could be determined by the bone scans. There was no discernible difference between the pre- and post-irradiation scans taken at monthly intervals until six mo post-irradiation, nor was there a difference between the irradiated and non-irradiated areas in the same monkey.

Although a routine procedure was developed to be used with human or primate subjects that resulted in computer-constructed emission tomograms of excellent quality, as with the conventional bone scanning, no difference was detected between control and irradiated monkeys or between the irradiated and non-irradiated bone within the experimental animals at any time up to six mo post-irradiation (Figs. 3a \& 3b).

\section{Discussion.}

Although most authors agree that it is difficult, if not impossible, to see any changes radiographically in the bone as a result of therapeutic irradiation, two investigators $^{5,6}$ found some changes due to $\mathrm{kVp}$ radiation. In the present study no changes were seen radiographically in the experimental group, presumably because histologically the bone with decreased vitality had not been destroyed, and the immature proliferating bone was not sufficiently calcified to be radiopaque.

Blood flow to a particular bone and that bone's metabolism have been considered the 


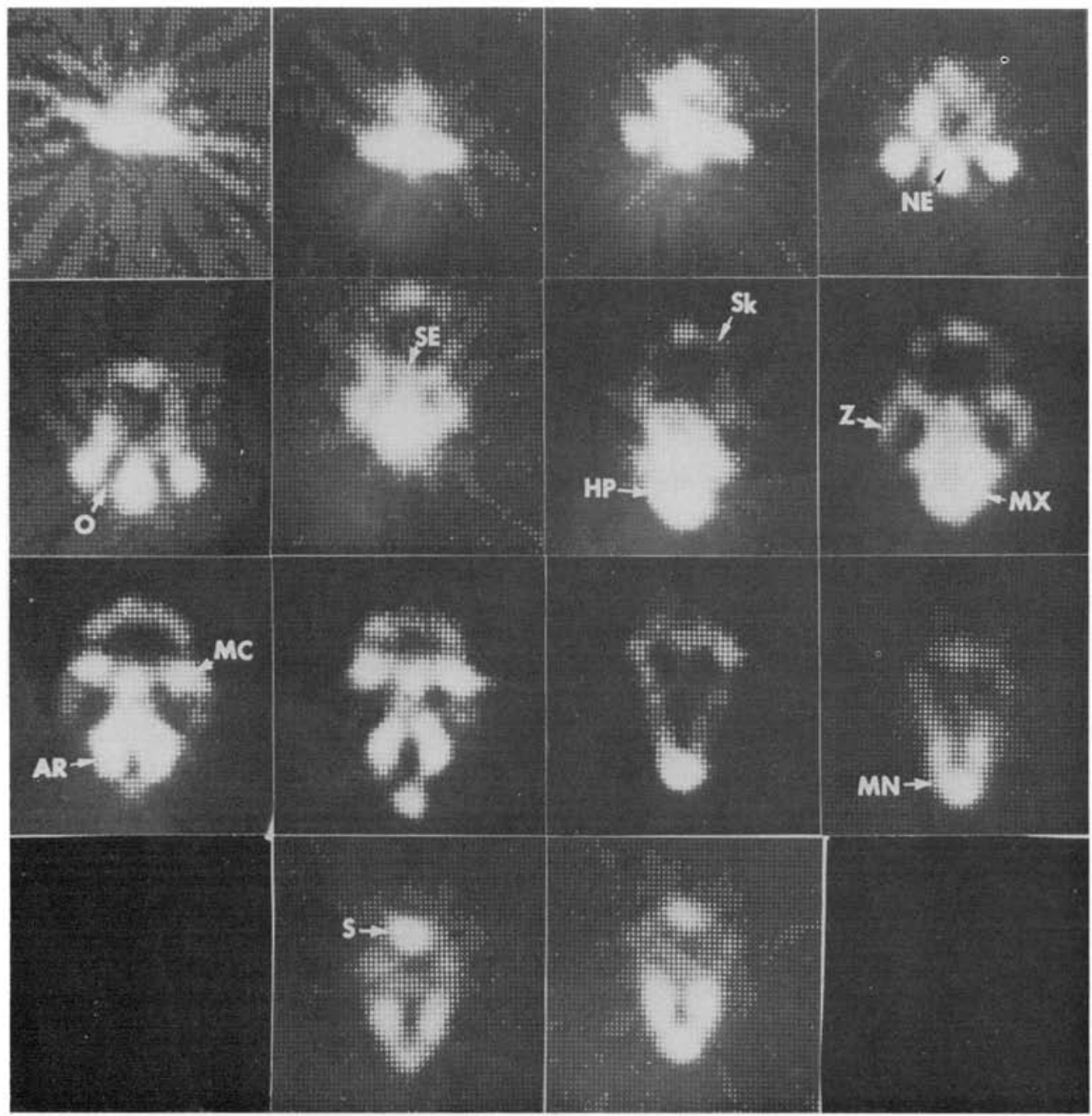

Fig. 3a-Control monkey.

determining factors in the distribution of the bone-seeking radioisotopes in bone scanning procedures. ${ }^{7-10}$ Capillary or barrier permeability ${ }^{11-13}$ and the volume of exchangeable bone pool ${ }^{10-12,14}$ are also of prime importance. Anticipating a dramatic change in the blood flow and perhaps the capillary permeability, we thought bone scanning and emission-computed tomography would provide an insight into the condition of the mandibular bone following radiation. Although six mo seems a short time for radiation damage, $33 \%$ of osteoradionecrosis occurs within six mo post-irradiation and $61 \%$ within one yr. ${ }^{15,16}$ Therefore, the predisposing conditions were assumed to be present within six mo post-irradiation. Early experience with a single-photon emission tomographic system in the head and neck area showed that useful diagnostic information can be obtained about tumors, infection, bone grafts, and post-irradiation osteonecrosis. ${ }^{17}$

King et $a l .{ }^{10}$ have developed a model having phenomenological parameters as variables for predicting local radioactive tracer accumulations in bone. They concluded that local blood flow and the volume of exchangeable bone pool exerted the greatest influence on local accumulation of radionuclides. They found that any clinically evident image change required simultane- 


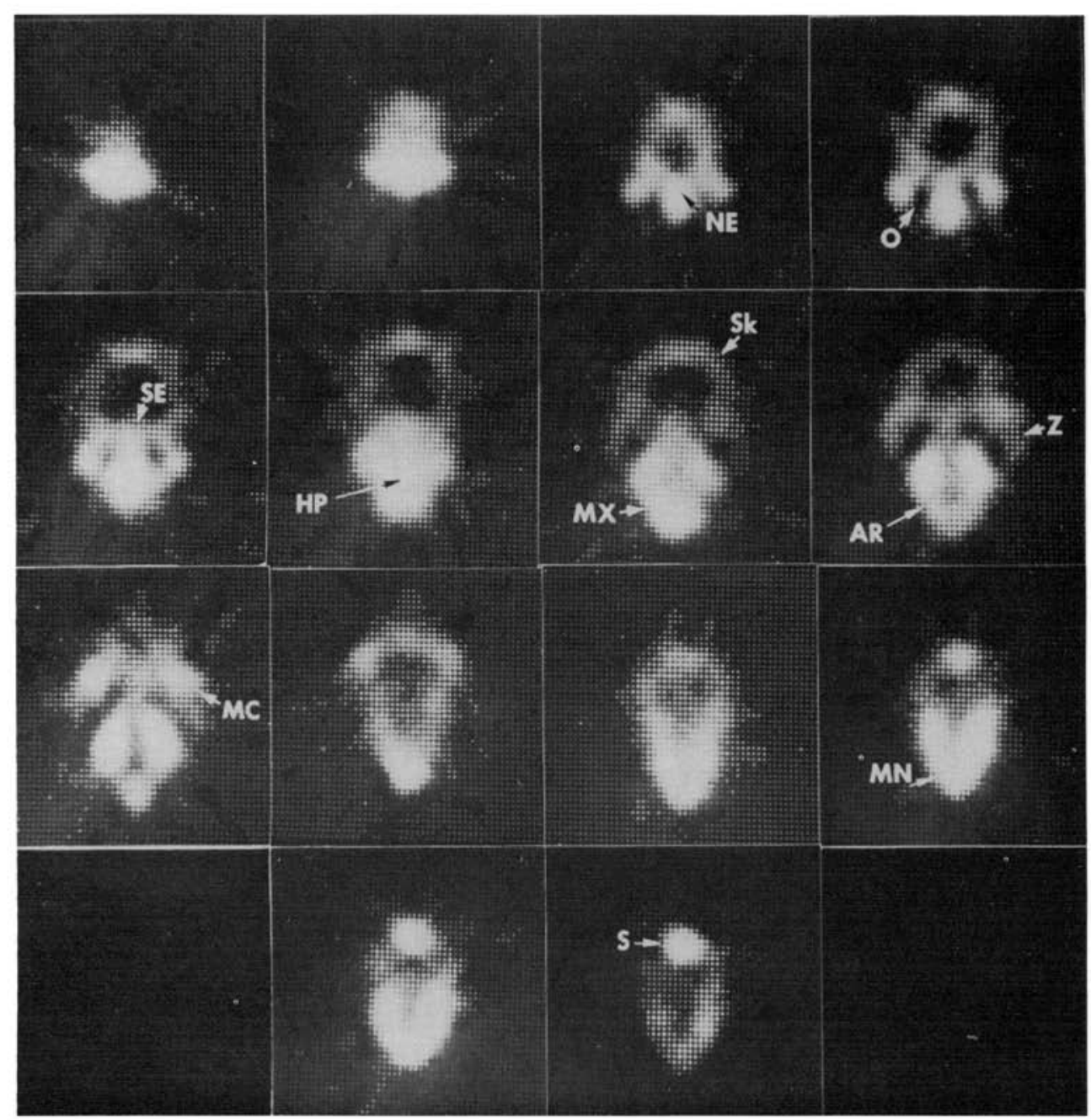

Fig. $3 \mathrm{~b}$ - Six-month post-irradiation computer-reconstructed tomograms extending from top of cranium (upper left) to lower border of mandible (lower right). Sections are $7.6 \mathrm{~mm}$ thick and oriented with monkey's face toward bottom of page and viewed from above. (SK) skull; (NE) nasoethmoid region; (SE) sella turcica; (O) orbit; (Z) zygomatic arch; (HP) hard palate; (MC) mandibular condyle; (MX) maxilla; (AE) alveolar ridge of maxilla; (MN) body of mandible; and (S) spine.

ous change of several parameters. Also, changes in one rate-controlling factor can be easily balanced by changes in another.

In view of the dramatic changes seen histologically, it appears the bone scans and emission tomograms can be misleading as to the true condition of the irradiated bone. In this investigation the apparent lack of change of uptake of the Tc-99m stannous pyrophosphate was probably due to compensatory effects of the reactive proliferation of bone which increased the volume of exchangeable bone pool. The increased bone pool could balance out the decreased perfusion which decreased the local blood flow. This suggestion agrees with and supports the model proposed by King et al.

A quantitative procedure used with a computerized gamma camera, ${ }^{18}$ which is claimed to provide more clinical information than radiographs or scintophotos, may increase the sensitivity of the tests so that the bone changes can be detected. 


\section{Conclusions.}

A dose of external supervoltage radiation to the mandible equivalent to a tumoricidal dose in humans produced dramatic histological changes, including loss of osteocytes in the path of the beam, degeneration of the periosteum, fibrosis of the marrow with marked proliferation of new bone, obliterative endarteritis, and obliteration of many Haversian canals. The radiation produced no changes detectable by high resolution radiography, conventional bone scans, or computed emission tomography. The single photon emission scans and tomography most likely show no change due to the balancing of several determiners of radioactive tracer uptake in bone. The reactive bone proliferation, which increased the volume of exchangeable bone pool, is probably counteracting the influence of decreased perfusion or local blood flow.

\section{REFERENCES}

1. KEYES, J.W.; ORLANDEA, N.; HEETDERKS, W.J.; LEONARD, P.F.; and ROGERS, W.L.: The Humongotron - A Scintillation Camera Transaxial Tomograph, J Nucl Med 18:381-387, 1977.

2. KAY, D.B.; KEYES, J.W.; and SIMON, W.: Radionuclide Tomographic Image Reconstruction Using Fourier Transformation Techniques, $J$ Nucl Med 15:981-986, 1974.

3. ORTON, C.G. and ELLIS, F.: A Simplification in the Use of the NSD Concept in Practical Radiotherapy, $\mathrm{Br} J$ Radiol 46:529537,1973 .

4. ROHRER, M.D.; KIM, Y.; and FAYOS, J.V.: The Effect of Cobalt-60 Irradiation on Monkey Mandibles, Oral Surg 48:424-440, 1979.

5. BOND, W.R.; MATTHEWS, J.L.; and FINNEY, J.W.: The Influence of Regional Oxygenation on Osteoradionecrosis, Oral Surg 23:99-113, 1967.

6. MEDAK, H. and BURNETT, G.W.: The Effect of X-ray Irradiation on the Oral Tissue of the Macacus Rhesus Monkey, Oral Surg 7:778-786, 1954.
7. BELL, D.G.; McAFEE, J.G.; and CONSTABLE, W.C.: Local Radiation Damage to Bone and Marrow Demonstrated by Radioisotope Imaging, Radiology 92:1083-1088, 1969.

8. GARCIA, D.A.; TOW, K.K.; and WELLS, H.: Tc-99m Polyphosphate Uptake by Resorbing Bone, $J$ Nucl Med 16:528, 1975 (Abst).

9. VAN DYKE, D.C.: ANGER, H.O.: YANO, Y.; and BOZZINI, C.: Bone Blood Flow as Shown with $18 \mathrm{~F}$ and the Positron Camera, Am J Physiol 209:65-70, 1965.

10. KING, M.A.; KILPPER, R.W.; and WEBER, D.A.: A Model for Local Accumulation of Bone Imaging Radiopharmaceuticals, $J$ Nucl Med 18:1106-1111, 1977.

11. WINCHELL, H.A.: Mechanisms for Radiopharmaceutical Localization, $J$ Appl Radiol 5:176-177, 206-207, 1976.

12. JONES, A.G.; FRANCIS, M.D.; and DAVIS, M.A.: Bone Scanning: Radionuclide Reaction Mechanisms, Sem Nucl Med 6:3-18, 1976.

13. GARNETT, E.S.; BOWEN, B.M.; COATES, G.; and NAHMIAS, C.: An Analysis of Factors Which Influence the Local Accumulation of Bone-seeking Radiopharmaceuticals, Invest Radiol 10:564-568, 1975.

14. GENANT, H.K.; BAUTOVICH, G.J.; SINGH, M.; LATHROP, K.A.; and HARPER, P.V.: Bone-seeking Radionuclides: An in livo Study of Factors Affecting Skeletal Uptake, Radiology 113:373-382, 1974.

15. REGEZI, J.A.; COURTNEY, R.M.; and KERR, D.A.: Dental Management of Patients Irradiated for Oral Cancer, Cancer 38:994$1000,1976$.

16. BEDWINEK, J.M.; SHUKOVSKY, L.J.; FLETCHER, G.H.; and DALEY, T.E.: Osteonecrosis in Patients Treated with Definitive Radiotherapy for Squamous Cell Carcinomas of the Oral Cavity and Naso- and Oro-pharynx, Radiology 119:665-667, 1976.

17. BROWN, M.L.; KEYES, J.W.; LEONARD, P.F.; THRALL, J.H.; and KIRCOS, L.T.: Facial Bone Scanning by Emission Tomography, J Nucl Med 18:1184-1188, 1977.

18. MORLEY, T.R.; SHORT, M.D.; and DOWSETT, D.J.: Femoral Head Activity in Perthe's Disease: Clinical Evaluation of a Quantitative Technique for Estimating Tracer Uptake, J Nucl Med 19:884-890, 1978. 